\title{
Academic freedom and freedom of speech: the assault of vulnerability
}

Stuart Waiton

This author accepted manuscript is deposited under a Creative Commons Attribution Non-commercial 4.0 International (CC BY-NC) licence. This means that anyone may distribute, adapt, and build upon the work for non-commercial purposes, subject to full attribution. If you wish to use this manuscript for commercial purposes, please contact permissions@emerald.com

(c) (i) (2) 
Academic freedom and freedom of speech: The assault of vulnerability.

\author{
Stuart Waiton
}

\begin{abstract}
The UK government's attempt to 'prevent' terrorism and extremism in the university sector is rightly seen as an intolerant threat to academic freedom. However, this development has not come from a 'right wing' authoritarian impulse, but rather, replicates many of the discussions already taking place in universities about the need to protect 'vulnerable' students from offensive and dangerous ideas. Historically, the threat to academic freedom came from outside the university, from pressures exerted from governments, from religious institutions who oversaw a particular institution or from the demands of business. Alternatively it was been seen as something that is a particular problem in non-Western countries that do not have democracy. While some of these problems and pressures remain, there is a more dangerous threat to academic freedom that comes from within universities, a triumvirate of a relativistic academic culture, a new body of identity based student activists and a therapeutically oriented university management, all three of which have helped to construct universities as safe spaces for the newly conceptualised 'vulnerable student'. With reference to the idea of vulnerability, this paper attempts to chart and explain these modern developments.
\end{abstract}

Keywords: academic freedom; freedom of speech; censorship; vulnerability 
The lay public is under no compulsion to accept or to act upon the opinions of the scientific experts whom, through the universities, it employs. But it is highly needful, in the interest of society at large, that what purport to be the conclusions of men trained for, and dedicated to, the quest for truth, shall in fact be the conclusions of such men, and not echoes of the opinions of the lay public, or of the individuals who endow or manage universities To the degree that professional scholars, in the formation and promulgation of their opinions, are, or by the character of their tenure appear to be, subject to any motive other than their own scientific conscience and a desire for the respect of their fellow experts, to that degree the university teaching profession is corrupted; its proper influence upon public opinion is diminished and vitiated; and society at large fails to get from its scholars, in an unadulterated form, the peculiar and necessary service which it is the office of the professional scholar to furnish (American Association of University Professors, 1915).

The above quote is from the Declaration of Academic Freedom and Academic Tenure, written over 100 years ago in 1915 by the American Economics, Politics and Sociological Associations. Of particular interest when reading this document is the unadulterated belief in the role of the academic to be 'dedicated to the quest for truth': Something that was understood to depend upon the absolute freedom of academics to pursue their ideas dependent upon their own 'moral conscience' as academics.

This paper aims to look at the assault on academic freedom. It does so in large part by looking at the attack on freedom of speech, especially in the university sector: The argument being that academic freedom and freedom of speech are intimately connected. An attack on 
free speech therefore will necessarily have repercussions for academic freedom and vice versa, and there are a growing number of attacks upon free speech today.

Within American universities, in 1915, pressures upon academics to conform to particular ideas came from outside of the university, from powerful vested interests or other conservative outlooks or interest groups. Today, concerns about economic and political pressures remain. However, there has been a more significant attack upon academic freedom over the last few decades that has comes from within the university itself (Altbach, 2001). This internal undermining of academic freedom and freedom of speech is now accelerating with the arguments related to safe spaces, trigger warnings, and the need to protect both staff and students from offensive words and behaviour.

\section{The Truth?}

Before looking at current developments regarding academic freedom in universities it is worth noting that within academia itself there has been a significant 'radical' critique of freedom of speech generated (in part) by a rejection of the idea of the 'pursuit of truth'. In one respect what we are witnessing in the challenge to academic freedom is the outcome of the collapse (or at least the serious decline) of liberalism, Enlightenment ideas and the belief in knowledge as a search for truth (Furedi 2007; Eagleton 2014).

Above we see how the various United States academic associations, in a matter of fact manner, discussed the essence of academic life being the pursuit of truth. It is difficult to find such a statement today within academia that does not come with some revision or amendment that runs counter to this sentiment. Indeed the very idea of the pursuit of truth, as Furedi 
notes, increasingly sounds somehow pompous and other-worldly, we are inclined to celebrate 'cultures' for example, rather than to encourage a sense of being 'cultured', the latter being tarnished with accusations of power and privilege. Despite the need for 'standards' there is a defensiveness in the promotion of this (ivory tower) idea that feels conservative and as Furedi notes in Where have all the intellectuals gone, ideas first promoted by individuals like Michel Foucault, that there are 'no truly universal truths' have become increasingly influential in academic circles (Furedi, 2004, pp. 4).

It is in part the diminishing belief in ideas themselves, perhaps especially in terms of how they relate to progress and the transformation of society that has undermined John Stuart Mills' arguments about liberty (Jacoby, 1999). For Mill, the importance of tolerance and liberty were in part, and arguably in large part, related to a belief in 'man as a progressive being' (Harcourt, 1999, pp. 187). His faith in rationality led to a robust defence of freedom and the free exchange of ideas - the more freedom the individual had the more society could find the truth and to progress. For Mill, writing in the middle of the nineteenth century, in the most dynamic country in the world, this coupling of individual freedom and social progress made sense. However, as social problems developed in capitalist society through the twentieth century, and indeed as alternatives to capitalism appeared to wane and to themselves appear to be oppressive, this faith in progress and humanity declined, and as with Foucault or Herbert Marcuse, not only were certain 'truths' seen as problematic, but so too was the very idea of Truth (Furedi, 1992, pp. 252-258).

If truth is problematic, indeed if the promotion of the pursuit of truth is seen as elitist and oppressive, then the freedom necessary to pursue truth is also problematic. Jason Walsh has observed in his study of the 'expanding empire of harm', that critical social thinkers like 
Herbert Marcuse as far back as 1965 were beginning to question the value of classical notions of progress, tolerance and freedom, including freedom of speech - the twin to academic freedom. For Marcuse, for example, progress was understood as profoundly negative, as 'bound up with intensified unfreedom.... the domination of man by man'. To press home the point Marcuse argues that, 'Concentration camps, mass exterminations, world wars, and atom bombs are no 'relapse into barbarism', but the unrepressed implementation of the achievements of modern science, technology, and domination' (Marcuse, 1972, pp. 23). Earlier, in his 'Repressive Tolerance' written in 1965, he discusses tolerance as a bourgeois oppressive concept, a mere ideology that favours and fortified the status quo of inequality and discrimination (Walsh, 2015).

Mill was famed for arguing the case for the one man having the right to speak even though his opinion was in opposition to the whole of humanity. But as faith in positive outcomes resulting from a clash of ideas declined, the argument grew that we should supress, rather than tolerate, reactionary ideas. As Coleman notes, for example, following the Second World War it was the Soviet Union under Stalin where we find these repressive ideas in a state form, indeed it was here that the idea of limiting hate speech emerged - something Western nations opposed as illiberal and authoritarian (Coleman, 2012). However, in the 1970s this defence of speech began to change and perhaps most importantly began to change for radical individuals and groups so that by the 1980 s the idea of 'hate crimes' developed and over the next two decades words came to be seen as causing 'trauma', particularly for 'vulnerable groups' (Waiton, 2019).

Amy Adler describes the 'radical' challenges to the idea of freedom and tolerance that developed within two left-inspired schools of thought, schools of thought that sought to 
regulate speech. She observed, 'The feminist anti-pornography movement, led by Catharine MacKinnon, and the anti-"hate speech" school, led by a group of legal scholars... wish[ed] to prohibit speech that harms historically victimised classes of society' (To get a sense of MacKinnon's influence, she was made the first Special Gender Adviser to the Prosecutor of the International Criminal Court in 2008). These developments, Adler notes was, 'nothing less than a war on traditional First Amendment jurisprudence' (Adler, 1996, pp. 1500). One of the dangers in the approach of these 'schools', Adler believed, was that in their attempt to protect vulnerable groups from offensive images and words, language took on a life of its own and the intension behind the use of words vanished. Ultimately this resulted in not just racists but also anti-racists and equality campaigners being targeted for their own use of certain words because, 'Intension and effect are ultimately disjointed' (Adler, 1996, pp. 1572).

A key reason for this censorious development within the left, Adler usefully notes, was that 'activist speech' was no longer seen as 'an agent of social change' (Adler, 1996, pp. 1567). If the First Amendment existed alongside slavery, the argument went, then why should we have faith in freedom of speech as a vehicle for liberation?

For critics of these developments, like Walsh and Adler, it was not new ideas themselves or a more nuanced understanding about how the world worked that undermined the idea of tolerance and freedom of speech. Rather, in this radical guise, it was, what Russell Jacoby calls the 'end of utopia' or the loss of belief in the possibility of radical social change and of human progress that led academics and activists to turn their backs on what was now seen as a futile or fictional search for 'truth'. More than this, Jacoby argues, with the decline of the 
'old' enlightened left, liberalism lost its backbone and the ideals of liberty and freedom began to wither (Jacoby, 1999).

In the UK, one of the outcomes of the decline of the labour movement and the diminished sense of political possibilities, by some of those on the left, was that sections of society who had previously been understood through the political category of 'oppression' increasingly became reconceptualised through a more therapeutic prism and were relabelled as 'vulnerable groups' (Waiton, 2019). As this projection of 'vulnerability' became normalised, new laws increasingly developed in Britain to protect people from offensive behaviour and words (Waiton, 2019). Over the next two decades the category of vulnerability, Furedi (2004) argues, both remained associated with these 'vulnerable groups', but in culture and law became a more universalising characteristic that helped to repose the understanding of harm. Through the prism of vulnerability the meaning of harm expanded, a key dimension of this being a profound elevation of the sense of emotional vulnerability often associated with the idea of being offended. Within this framework language has been further problemtised and increasingly understand as a form of abuse and violence.

On both sides of the Atlantic, as we moved into the new millennium, the philosopher Joel Feinberg noted, we had moved from Mill's harm principle to the offence principle (Stanford Encyclopaedia of Philosophy, 2017). The consequence of this move for academic freedom and freedom of speech are significant, perhaps less in the overt punishment of those committing offence, although this is a reality, than in the cultural climate and acceptance of the limitation of words and ideas within the academy that are understood to cause harm.

\section{Preventing harm}


Before we look at what Ben Garrison has called the rise of the 'crybullies' in universities, it is worth unpicking the UK government's anti-terrorism Prevent strategy, or duty, and to look at the question and meaning of tolerance to illustrate the extent to which modern day 'Western values' are in many respects a threat to the very idea of liberty they, in theory, uphold (Garrison, 2015).

The government's Prevent strategy is of significance because it is an example of an overt use of state power over universities and as such it has been widely condemned, so widely in fact that it would be hard to find a university Principal or indeed many university lecturers across the whole of the UK who enthusiastically support this initiative. The lecturer's union, the UCU, for example, condemns Prevent as a threat to academic freedom, to legitimate campus activism, for its potential racism and for encouraging lecturers to become spies (UCU, 2015). And yet when we examine the wording and the framework of understanding in Prevent we find many of the wider concerns about 'vulnerable students' that are more readily endorsed by academics and academic institutions, are central to this government anti-terror initiative. On consideration it appears that the seemingly authoritarian British state and their more liberal and radical university critics have more in common than they might imagine. The opposition to Prevent is interesting because it reflects a flawed sense that the threat to academic freedom comes from a right wing authoritarian state imposing its will on the institution when the reality is both that this state is largely a fiction and that the threat to academic freedom comes more from within the academy itself and often from the more seemingly liberal concerns about protecting the vulnerable. As Williams notes, 'A focus on the requirements of the Prevent Duty ignores the less obvious but therefore more insidious restrictions on academic freedom that emerges from within universities from students, 
institutional expectations and a desire not to cause offence'. (Hudson and Williams, 2016, pp. $\mathrm{xv})$.

The duty to 'Prevent' extremism in universities is developed in Section 26 of the CounterTerrorism and Security Act 2015. The guidance to this act has now been passed onto universities who in their turn are attempting to enforce this legislation that makes it a legal requirement for universities to prevent extremism within their institutions, by, in part, monitoring the reading material of their students or limiting certain outside speakers, a move condemned by Williams who notes that this 'risks turning universities into agents, rather than critics, of the state' (Hudson and Williams, 2016, pp. xv).

This Prevent strategy was first published by the government in 2011 'as part of their overall counter-terrorism strategy CONTEST', with the stated aim being to 'reduce the threat to the UK from terrorism by stopping people becoming terrorists or supporting terrorism' (UCU, 2015). In this act we find a specific duty on behalf of the authorities, including colleges and universities, to have 'due regard to the need to prevent people from being drawn into terrorism' (my italics). Here 'extremism' is defined as, 'Vocal or active opposition to fundamental British values, including democracy, the rule of law, individual liberty and mutual respect and tolerance of different faiths and beliefs' (UCU, 2015: 2).

The attempt to force universities to overtly monitor their students and limit and regulate the ideas they can engage with sits uncomfortably with the idea of 'individual liberty' promoted by the government as a British value. Academic freedom, in the sense promoted by the American Association of University Professors, means that there should be no limits upon the ideas, issues or reading material available within a university or no limits that lecturers 
themselves do not frame. The Prevent strategy is a clear negation of this approach to academic life and has rightly been condemned by the UCU and others.

This contradiction, of the British government promoting 'liberty' on the one hand while undermining it on the other, appears to be an ongoing problem for Western government's when dealing with modern day terrorism. Democratic governments denounce terrorists and denounce them for undermining 'our way of life' - including our liberty and freedom - while at the same time creating new laws and initiatives to clamp down on various freedoms and develop oppressive forms of policing. In France, for example, the comic Dieudonne M'bala M'bala was arrested after the Charlie Hebdo murders for writing 'I feel like Charlie Coulibaly'. Others were arrested for speech crimes leading to the French League of Human Rights denounced the state action for imprisoning 'drunks and fools' (BBC, 2015). In the UK in 2019 the police used the Terrorism Act 2000 in a failed attempt to demand that journalists hand over notes from their interviews with terrorist Shamima Begum, the notorious 'jihadi bride'. Despite this case failing, free speech advocate Mick Hume noted that this was helping to create an authoritarian climate within which journalists feel the state 'looking over their shoulders' when dealing with terrorist reporting (Hume, 2019).

The Prevent strategy is one of a number of terror related laws that limit freedoms. More generally the attack on freedom of speech has also come with laws, initiatives and campaigns to deal with 'offensiveness' and 'hate'. (Waiton, 2012; Rooney, 2018). What is particularly interesting from our perspective when looking at the Prevent strategy and its explanation of British values is the seemingly interconnected ideas of 'individual liberty' with the idea of 'mutual respect and tolerance of different faiths and beliefs'. At one level, this statement could be seen as unproblematic - being tolerant of religious differences and beliefs has been 
a central plank of liberalism since Locke's A Letter Concerning Toleration, written in 1689, and more particularly since J.S. Mills On Liberty. However, tolerating something and respecting something is very different, indeed, the conflation of the two terms reflects an underlying contradiction in the modern idea of tolerance Furedi (2011) has observed, what we in the West mean by tolerance has changed and in many respects modern day 'tolerance' means the opposite to what it previously meant. To be tolerant in the past meant accepting the right of people to hold and express different views without interference from the state - it was the basis of the argument for free speech and ultimately for the promotion of academic freedom. Today, this meaning has changed fundamentally and now, being a tolerant person, means being someone who is not offensive to others, someone who 'respects difference'. It is in fact the new basis for limiting freedom of speech.

Today the apparent British value of being tolerant is in fact a direct challenge to the idea of individual liberty because being a tolerant person or institution increasingly means regulating and restricting people who are deemed to be intolerant. In a university context it means managing and policing words and ideas that are seen as offensive and therefore harmful: Thou shalt respect others.

\section{Intolerant tolerance}

In looking at the changing meaning of tolerance it is worth starting with the classic work on liberty written by John Stuart Mill's in 1859. In Mill's work, to tolerate something, one first had to judge it, disagree with it but also accept that it should not be controlled by the authorities simply because one thought it was wrong or repugnant: You do not have to tolerate ideas that you agree with, you tolerate wrong ideas and behaviour, but also challenge 
what you see as reactionary viewpoints and behaviour. For Mill, the principle was clear - as long as no physical or economic harm was done to an individual, ideas and behaviour should be tolerated - even, and indeed especially, ideas that you found abhorrent or upsetting. 'Wrong' ideas or behaviour were useful for Mill because they continually encouraged society to challenge them, thus strengthening the understanding of ideas across the populace. This was important not only for the free development of ideas and beliefs but also, and equally, for the development of individual moral autonomy. He who lets the world choose his plan of life for him, Mill argued, has no need of any other ability than that of imitation: But this is not the action of a 'man'; it is merely the action of an ape. Part of the belief in the importance of personal moral development came from an idea that it was wrong to force beliefs onto people. The goal was to encourage a vibrant culture made up of autonomous individuals who were free to think and act and also to challenge one another's behaviour. For the German philosopher Immanuel Kant, respect was given to people and their freedoms as part of a belief that this would help encourage the development of reason and conduct which genuinely belonged to each individual. Everyone was to become judgemental, to make their own judgements and decisions, and to take responsibility for their own actions (Mill, 2011).

Incorrect or wrong choices were not centrally important for Mill. More crucial was what manner of men and women it was that were acting in the first place; what type of individual was making the choice. In a sense, as Furedi (2011) notes in On Tolerance, Mill wanted everybody to be a heretic - to be a free choosing person - rather than a sheep that simply repeats the latest correct and inoffensive mantra. Tolerance was difficult. Accepting rather than punishing those whose views and behaviour you hated required strength and maturity, and most of all a belief in the importance of freedom. As George Orwell noted, if democracy means anything it is the right to tell people what they do not want to hear (Orwell, 2000). We 
retain our dignity, Furedi argues, only by insisting that no official can withhold an opinion from us. Likewise, we only become robust human beings by being faced with conflict, by encountering difficult and even offensive ideas and forms of behaviour. Words may well hurt, but dealing with them can develop individual character, a more vibrant public life and a more articulate society.

Today, in comparison, Furedi argues, the meaning of tolerance has been transformed. This has developed over many decades across the Western world, he notes, with little discussion or clarification about what this thing tolerance now actually means (Furedi, 2011, pp. 1-25). Tolerance now means the opposite of what it used to. It is not about judging, but about being non-judgemental, not about speaking your mind but about limiting hurtful speech and behaviour, not about limiting state power so allowing free expression but about increasing state power to protect people who are seen as fragile and vulnerable. It has become a personal characteristic; a badge of decency - 'I'm a tolerant person' - disconnected from the idea of freedom or even thought. It has also become about 'respecting difference': not respecting individual freedoms as such, but 'respecting' statically-defined groups and identities. It has also become a form of politeness based on an understanding that these, officially defined, groups and identities are easily bruised by things we say, beliefs we have and types of behaviour we exhibit. Consequently, having offensive ideas or behaving in an offensive way is understood to cause alarm or distress and needs to be regulated or made illegal. Rather than tolerance being about individual freedom and the autonomy of individuals being respected, it has become about respecting groups and group identities and protecting them from harm where harm is no longer about physical or economic harm - but about emotional harm caused by words. 
Until relatively recently 'tolerance' was the basis upon which free speech was built, today, through this transformation of its meaning it is the basis upon which new laws are developed that undermine freedom of speech.

\section{The infantilisation of university life}

Discussing the Prevent strategy, Bill Durodie (2016) argues that an essential part of this act is the attempt to protect students from certain 'extreme' ideas at university. Students are represented in an infantile way, he argues, but he notes, this is not something new to universities that have in fact been treating, what are adults, like children for some time. We already, he argues, treat students as fragile or vulnerable individuals who need to be protected, and as such the British government are simply reflecting this diminished view of students within this strategy. Concerns have been raised about the growing therapeutic nature of university life. Furedi for example, has carried out work looking at the infantilisation of students, noting the growing trend for parents to accompany students to university open days or for parents to act on their grown up children's behalf when dealing with academic disputes. The more infantile adult, he argues, has been encouraged by the psychologisation of existential problems, with increasing numbers of children in schools being socialised to understand difficulties in mental health terms and to foster a sense of dependency upon experts and to embody a more fragile sense of self. One outcome he believes is that when these young people face difficult issues or ideas at university they are more inclined to 'state that 'I am offended' instead of 'I disagree', (Furedi, 2017, pp. 6-15).

Durodie points out that the key idea behind the Prevent strategy is summed up in the sentence referring to the need to 'prevent people from being drawn into terrorism' (my italics). This 
idea that students are somehow 'drawn into terrorism', Durodie argues, is a particularly passive and infantile view of university students, who are in this instance, not represented as moral agents who are making conscious choices, but as fragile individuals who are coaxed into doing things against their (limited) will. In the 'Revised Prevent duty guidance: for England and Wales', the term 'vulnerable' is used 17 times, with talk of, 'the public should understand what radicalisation means and why people may be vulnerable to being drawn into terrorism as a consequence of it', and the need to 'recognise vulnerability to being drawn into terrorism'. Like young children who are groomed by paedophiles, here we find terrorist are no longer free individuals who make immoral choices but diminished, vulnerable subjects who need 'support' to prevent them being 'radicalised' (Home Office 2019). (On this basis I could reinterpret my university experience as being vulnerable to radical left wing ideas).

The interesting thing about the Prevent strategy is that despite the huge amount of criticism it has faced from academics, hardly anyone appears to have noticed or found a problem with this representation of grown adults as 'vulnerable'. This is because the idea that students are vulnerable and need to be protected has been institutionalised within universities themselves, accepted and promoted by many academics and celebrated by student activists in their promotion of universities as 'safe spaces', witnessed in the growing concern about 'microaggression', and seen with the growth of 'Trigger Warning'. These new developments that are growing in the United States of America and the UK are becoming increasingly influential and are a new threat to both free speech and academic freedom.

\section{Trigger Warnings}


Trigger warnings are advisory labels that classify books, journal articles, films or other material to be used by a student that may 'traumatise' them in some way. The warnings are used to protect students from issues or words related to 'racism, classicism, sexism, heterosexism, cissexism, ableism and other privilege and oppression' (Hume, 2015, pp. 130). Searching the Guardian newspaper, it is noticeable that there were no articles about trigger warnings until 2014. This first article raised concerns about trigger warnings in the US that forced labels onto books, including The Great Gatsby. The warning read, 'Warning: suicide, domestic abuse and graphic violence' (Guardian, 2014). Interestingly, this development of trigger warnings appears to have been pushed less by university management in the UK than by academics who have taken it upon themselves (often with the support of student organisations) to protect their students from certain material. It is also strongly endorsed by student union association who argue that these warnings encourage debate because they prevent students from being traumatised and so enable them to take part in that debate (Oxford SU). Increasingly, however, university management, as part of their wider therapeutic approach to students, are beginning to react to concerns about the content of lectures and encourage the use of trigger warnings.

University College, London, for example, has told students studying the archaeology of modern conflict course that they can leave class if they find discussions 'disturbing' or 'traumatising'. In 2019, in the UK, the head of English at the University of York apologised to 'students who were offended when they came across the word 'negro' in lecturers about the work of the African-American sociologist W.E.B. Dubois' (AFAF, 2020). The lecturer has now incorporated trigger warnings for his lecturers. Furedi, in response, argued that, 'The obsession with the policing of language has become a caricature of itself. The word negro, which was used by pan-Africanists to refer to themselves, is now rebranded as a source of 
distress by students who do not have a clue about what racism means' (AFAF, 2020). With the Dubois case we find rather than a discussion and clarification about how to understand the term negro in its historical context, the ignorance of the students is endorsed based on their emotional reaction and belief that words they find offensive should not be used.

Part of the role of trigger warnings is to allow certain students to avoid reading or viewing certain materials that they believe will be emotionally upsetting for them. This has led to concerns being raised about this narrow classification of complex material and the potential for limiting knowledge and education at universities. A Harvard Law professor has written about her concerns that students are being advised not to attend law classes on sexual violence in case it makes them feel uncomfortable (New Yorker, 2015). It is difficult to get a sense of the extent to which trigger warnings are used in the UK, partly because they are often developed informally. However, one examination of Glasgow University, using a Freedom of Information Request, found trigger warnings on the modern language course relating to fairy tales by the Brothers Grimm, there were trigger warnings on the classics course, where frequent 'flags' were issued to alert students to content that is different to their own culture, the theology course had trigger warnings regarding torture and violence, and other warnings were found on the universities history course and veterinary course - the veterinary trigger warning was introduced after a complaint of sexism by a student regarding a ‘jokey’ PowerPoint slide about animals (Grant, 2019).

Despite trigger warnings rarely being a proscribed university policy there is concern that they act as a form of pressure on lecturers to turn their lecturers into safe, or safer, spaces and to avoid controversial ideas and issues. This is likely to be enhanced by the elevated understanding of 'trauma' associated with the idea of trigger warnings. Ecclestone believes 
that, 'This creates....a growing tendency towards small, almost unconscious, incidents of selfcensorship and self-editing and a growing sense of hesitancy in how we teach' (Ecclestone, 2016, 173).

In the UK, there is a growing trend for management of universities to increasingly relate to students, to student associations and what they call the 'student experience', to ensure that student needs are being met. There is also a wider cultural pressure and indeed legal pressure regarding diversity and the legal need to promote diversity. The Equalities Act 2010, for example, makes it a legal duty for universities to ensure a duty of care regarding offensiveness in relation to people with 'protected characteristics'. Both the cultural and legal pressure helps to heighten an awareness of the need to be inoffensive and acts as a form of pressure on university management and upon lecturers. As one lecturer noted,

Students are already primed from university marketing and induction material to expect their views to hold sway and that the function of all who work at the university is to meet their needs. Nowhere are the new recruits inducted into the concept and practice of academic freedom. We tell them we will listen to their voice when they speak but rarely teach them that they must allow others the same freedom (Hafez, 2016, pp. 113).

As Hume notes, trigger warnings began as a therapeutic tool to help individuals with PTSD avoid viewing certain images or ideas that they may find particularly distressing and yet this form of self-censorship related to individuals with an anxiety disorder has been expanded to university materials and could have a significant impact on course materials, teaching practices and the language used by academics. This is not direct censorship but relates to 
what Mill saw as a more significant threat to freedom - the cultural climate that suffocates experimentation, free thinking and expression. The very idea of a trigger warning risks turning an increasing number of issues, ideas and even words into problems that are understood in terms of actual harm done to student wellbeing. One concern, raised by Greg Lukianoff and Jonathan Haidt is that this approach to students can encourage rather than resolve psychological difficulties some students have. As Jarvie notes with reference to their work, 'In The Atlantic, Greg Lukianoff and Jonathan Haidt have suggested that a campus that coddles students and encourages them to police each other's speech could have a detrimental impact on students' mental health, teaching them to 'think pathologically', (Jarvie, 2016, pp. 195).

The subjective nature of experiencing trauma also means that an increasing array of issues and ideas are likely to become 'triggers', potentially encouraging a form of defensive teaching where playing it safe, self-censoring and treating ideas as a potential form of harm becomes the norm.

\section{Microaggression}

Another development in US universities and one that is being adopted already in the UK is the idea of microaggression. Promoted as a form of hyper-awareness to the need to regulate language, microaggression explains the 'real' meaning behind everyday comments that are made between people. The list of microaggression terms, developed for use in the University of California, Los Angeles include comments like, 'Where are you from', which implies 'You are not a true American', and, 'There is only one race, the human race' which is said to be a 'denial of the significance of a person's ethnicity' (UCLA, 2010). Both these terms are 
said to be a form of racism, regardless of the intention of the person who is speaking and this topic is now being discussed in the UK in the framework of 'everyday racism'.

The potential for the idea of microaggression to determine future academic behaviour can be seen in the example of the UCLA professor of education who changed the capitalised, 'Indigenous' to, 'indigenous', for grammatical reasons, and faced a protest and sit-in, for 'disrespecting the student's ideological point of view'. Writing about the case, MacDonald argues that despite the professor in question being experienced and well respected, and despite a key concern being about grammar - the use of a capital 'I' - the students were appeased by management, thus conferring legitimacy on their claims of racism. The professor's teaching was changed to incorporate other lecturers (MacDonald, 2014).

The fact that an individual in this context can be understood to be disrespectful or even racist, regardless of any intention, is particularly problematic for universities. Microaggression is understood to often be 'unwitting'; we do not know we are racist. In many respects the decision about a person's racist behaviour can only be decided by the 'victim' and their interpretation of what has been said and done. The founder of the term microaggression explained that, 'Nearly all interracial encounters are prone to the manifestation of racial microaggression' (Sue et al., 2007). Taken literally, the potential for interracial discussions to take place without microaggression seems unlikely and the potential for challenging academics in terms of their use of (unintended racist) language is vast. The student campaign around microaggression in Harvard, for example, quickly spread to Oxford University and is ongoing (Tumblr, 2016). 
The concern about microaggression, like trigger warnings, comes less from university management than from student activists and 'radical' academics. However, some universities, like the University of California, have drawn up a list of potential microaggressions. In the UK some universities are also beginning to take a more proactive approach to the issue. Sheffield University for example recently advertised for posts for 20 paid students to tackle micoraggression amongst the student body. The new recruits' job will be to listen to other student conversations and to intervene when they hear 'subtle but offensive comments' and to encourage 'healthy conversations' (Slater, 2020).

Furedi believes that the idea of microaggression is the most significant issue raised in the current phase of the culture war in higher education, arguing that, 'Through offering a widereaching account of prejudice, this concept helps to encourage and validate a disposition to be outraged, and fuels a sense of hyper-vigilance towards potential acts as bias' (Furedi, 2017, pp. 107). He hints at a Kafkaesque development where the profoundly subjective nature of microaggressions elevates further a cultural anxiety regarding the use of words or even letters, potentially leading to a situation where lectures, rather than being free flowing and experimental become increasingly scripted, to the letter, to avoid accusations of harm to students. After all, 'Once the doctrine of microaggression is normalised, almost any ambiguous gesture or word can become the medium for conveying suspicion and conflict' (Furedi, 2017, pp. 110).

\section{Safe Space}


The idea of a safe space is a place/space where individuals can feel safe - not threatened - by certain types of behaviour, ideas and language with which they are uncomfortable - a place where you have a sense of ontological security

One of the earlier papers to discuss the 'educational metaphor' of the 'safe space' was written in 1998 and was, noticeably, related to a discussion about school children rather than university students (Boostrom, 1998, pp. 397). Interestingly, this paper concluded that this well intentioned educational idea, 'unintentionally undermines critical thinking' (Boostrom, 1998, pp. 397). The idea of a safe space within educational institutions has changed over time, but with, the emotional wellbeing of the student at its heart, this idea, when developed in practice, has the potential to undermine academic freedom and education. Holley and Steiner have observed that, in part, the idea of a safe space was developed to encourage risk taking and honest expression (Holley and Steiner, 2005, pp. 49). It did not refer to feeling 'comfortable' because for students to grow and learn they must confront issues that make them uncomfortable and force them to struggle with who they are and what they believe. However, they also note that the idea of a safe space is not about physical safety but about protecting a student from psychological and emotional harm (Holley and Steiner, 2005, pp. 50). Here we find a potential contradiction, particularly when it comes to who is defining psychological and emotional harm and what issues, ideas or words can be said to create a problem for students: As we have seen with the examples of trigger warnings and microaggression, the number of issues, words and ideas that can become problematic is expanding considerably. Holley and Steiner recognise this problem when discussing what students mean by 'non-judgemental or non-critical instructions or fellow students'. As they argue, 'Does any critique leave some students feeling threatened and unsafe? Are there many 
or some students who will not feel safe in any classroom where their ideas or beliefs are challenged?' (Holley and Steiner, 2005, pp. 50).

The UK's National Union of Students (NUS) has a 'safe space' policy that is endorsed by many university NUS organisations. These polices relate to harassment and intimidation but also argue that student's should be free from 'judgement'. Many of the statements relating to safe spaces refer to the feelings of the individual student regarding feeling 'isolated', feeling 'uncomfortable', not feeling welcome or simply fearing that this may be the case. Relating to microaggression, the safe space policies discuss 'everyday terms' like 'gay' (meaning bad), which cannot be allowed because they 'can also cause offence or reinforce negative stereotypes'. At Bristol University the idea of safe spaces has been incorporated into the student union code of conduct. Within this code an Anti-discrimination and Harassment statement has been produced and representatives are encouraged to read it out 'at the beginning of all large SU activities'. Here the starting point appears to be a presumption of student vulnerability and a need to illustrate the protective nature of the student association where 'members are free from fear' (Bristol SU, 2016).

In the US a race related protest in Missouri took the form of defending a safe space and challenging microaggression. Here the administration backed the protestors and the Missouri University Police Department put out a call for people to identify anyone who used 'hurtful speech', something they accepted was not criminal, but could be used as a basis for a university disciplinary (Griswold, 2015). Despite what may be legitimate issues being raised here, a major concern is that any disagreement with the 'radical' protestors is leading to claims of microaggression and the term 'safe space' is being used aggressively to restrict reporting of the issue (Friedersdorf, 2015). In other universities there has also been a move to 
prevent and even discipline staff who do not prevent 'cultural appropriation' by disregarding concerns about 'offensive' Halloween costumes (Stack, 2015). Another example of the aggressive use of 'safe spaces', can we seen on YouTube regarding an Atheist Society meeting at Goldsmith University in London that was disrupted by the Islamic Society (a disruption supported by the feminist society) due to the belief that the speaker was Islamophobic. The speaker Maryam Namazie, a self-proclaimed communist feminist who attacks what she sees as right wing Islamic ideas, was confronted by members of the Islamic society who used the term 'safe space' repeatedly to interrupt her speech (Namazie, 2015).

The idea of safe spaces has grown in universities in both North America and the UK. These 'spaces' are, in many respects, anti-free speech zones or areas where students will not feel challenged or offended by views, ideas or words they disagree with or find offensive. When adopted as an official university approach, like in Sheffield, or when adopted by student associations, these safe spaces become enforced zones of 'correct' behaviour for all students (and potentially lecturers). When safe spaces incorporate concerns about microaggression the potential for the policing of language and behaviour is extensive (Hunt, 2015). At Oxford University students have campaigned to have the statue of Cecil Rhodes removed from campus because of his colonial past. Beyond politics however the form this protest takes relates to the idea of student 'safety' and vulnerability, with, for example one campaigner arguing that, 'There's violence to having to walk past the statue every day'. Here we find not only words or ideas but a statue needs to be taken away to protect students from this form of 'violence' (Slater, 2016).

It appears that once the idea of 'safety' is adopted in relation to ideas - within the context where 'harm' relates to emotional sensibilities - the potential for restrictions, censorship and 
the regulation of free speech and academic freedom is enormous. Concerned with this development in the UK the organisation Academics for Academic Freedom (AFAF) was set up within the UK.

A safe space is perhaps better thought of as an attitude rather than an actual place, an attitude or etiquette that incorporates trigger warnings and microaggression and, as the name suggests, elevates the issue of safety, but in particular, does so with reference to ideas and words rather than any physical threat. Interestingly, Furedi traces the origins of this idea back to Karl Mannheim's idea of 'social distancing' and boundaries set up between groups. One aspect of this distancing was its development and persistence in authoritarian civilisations seen with the emergence of totalitarian movements in the interwar period (Furedi, 2017, pp. 72). Fear and the loss of a civil society, and the emergence of 'safe spaces' kept people away from one another and helped the authoritarians to remain in power. In contrast, democracies break down the need and existence of safe spaces - facilitating civil society and a more Millsian free flow of ideas and interactions in what could be described as a tolerant space. Part of the reason for the emergence of safe spaces Furedi believes, is the elevation of safety as a new absolute (Furedi, 1997). In the context of a classroom, Barrett's research suggests that students tend to support the idea of this type of space as one where there identity is confirmed and their ideas are appreciated rather than challenged - something Furedi believes engages with a more therapeutic sense of both self and of education as a process not of developing ideas but developing ones self-esteem (Furedi, 2017, pp. 74).

\section{Censors}


In the UK, what are called no platform policies have developed since the 1970s, these are policies that prevent certain invited guests from speaking to students due to their beliefs. Initially, these policies adopted by student associations, aimed to ban fascist organisations like the National Front or the British National Party from speaking. The no platform approach has been broadened in recent years to include bans on speakers who are perceived to be racist and more recently anyone who is associated with hate crimes or hate speech. Most particularly, concerns about transphobia have seen famous feminist academics being prevented from speaking. From concerns about extreme political ideas being promoted at university the trend has developed to expand the areas of censorship through the language of limiting 'hate' and more particularly through the concerns about emotional harm generated by 'offensive' words and images.

In 2015 the online magazine spiked online analysed the restrictions on freedom of speech within UK universities by both university management and by student associations. They found that when looking at the combined approaches of university management and student union policies 80 percent of universities place binding restrictions on freedom of speech: Half the universities surveyed across the UK had explicit bans, while many others used what spiked argued were 'more insidious' restrictions that referred to 'offensive or insulting speech' (Slater, 2015). Student Associations led the way, with 51 percent having banning policies, compared to only 9.5 percent of university institutions having policies of this nature. Thirty one percent of university Free Speech policies, aimed at 'securing free speech within the law', actually place restrictions on 'offensive', 'controversial' or 'needlessly provocative' speakers on campus. Also 48 percent of universities are described in the spiked analysis as having 'censorious bullying and harassment policies'. 
Free speech codes were introduced in the 1986 Education Act. Aimed at ensuring 'freedom of speech within the law', subsequent laws, codes of practice and over enthusiastic university management, have meant these codes have in effect become used to censor rather than free debate. The University of Birmingham's code of practice lists 13 pieces of legislation passed since 1986 that may 'within the law' impinge upon freedom of speech. These include the Terrorism Act (2000), the Criminal Justice Act (2003) and the Equality Act (2010). Bolton University lists topics like abortion, immigration or animal experimentation that may, 'give rise to a reasonable apprehension that disruption or disorder may occur', and should therefore not be debated. Joanna Williams argues that, 'The legislation that has had the biggest impact upon free speech on campus is the Equality Act 2010, which offers people legal protection 'against direct and indirect discrimination, harassment and victimisation'” (my italics). Universities like Exeter University talk about the need to limit speech that can be deemed to be offensive and go beyond the letter of the law in insisting that, 'Students, staff, governors, the students' guild and visiting speakers are therefore required to demonstrate sensitivity to the diversity of the university community and to show others respect'. As Williams notes, freedom of speech is here understood to mean the freedom not to offend, and as author of Unlearning Liberty: Campus Censorship and the End of American Debate, Greg Lukianoff argues, 'By following a "sensitivity for everyone" as opposed to a "free speech for everyone" model, you create the risk that nobody will be allowed to say anything interesting at all' (Williams, 2013).

There is a growing trend in universities for speakers to be banned, often because their views are deemed 'unsafe'. In America it has been calculated that there have been 257 'disinvitation' campaigns in universities since 2000 (Cole, 2015). In the UK the well-known feminist Germaine Greer hit the headlines following a campaign to have her banned from 
speaking. Like another feminist, Julie Bindel who has also been 'no platformed', Greer was described as a transphobe and a campaign was launched to have her banned from Cardiff University. An abortion debate between two men was banned at Oxford University, because it was two men speaking and those 'without uteruses' were not deemed to be the correct people to speak on this matter and also because the discussion could impact on the 'mental safety' of students (a ban that was supported by the university for security and welfare issues). Cambridge University have withdrawn a promotional video containing the famous historian David Starkey because of concerns about his offensive views (views that are not expressed in the video itself) (O’Neill, 2015a).

The language of safety (and mental safety) is now used to restrict many 'incorrect' views. The University of East Anglia for example banned a local parliamentary UKIP (UK Independence Party (who oppose immigration)) candidate from speaking. The protest organiser explained that, 'This is about ensuring the UEA students are on a campus where they feel safe, secure and respected' (Hume, 2015, pp. 124). As Hume notes, the same students banning all sorts of individuals and ideas at their universities are the same ones who have expressed their outrage at the government's Prevent strategy and its attempt to ban 'extremism'. Similarly lecturer's organisations have protested about universities that restrict anti-Israel views (Alexander, 2014), while they themselves attempt to restrict potentially proIsraeli views through their promoted boycott of Israeli academics (Engage, 2015). Here we find a partial defence of freedom of speech based on the nature of the issue rather than a principled defence of freedom of speech in and of itself.

Remarkably, a former student of University College London who fought with the Kurds against ISIS was also banned from speaking because UCLU didn't want to take sides in the 
conflict. The college management sought advice from the police but heard nothing back so erred on the side of caution. As Brendan O'Neil notes, this should not come as a surprise considering the NUS rejected a motion condemning ISIS in case it was seen as Islamophobic (O’Neill, 2015).

It is relatively rare for speakers to be banned from universities in the UK but this is often because controversial speakers are rarely invited. However, what counts as controversial is itself expanding, as is the language associated with 'hate' and 'phobia'. For their part, once again, it is less the university administrators who are pushing this approach than student bodies and activists - with, at times, help and encouragement from some lecturers. University authorities are however, inclined to 'play it safe', literally, by adopting arguments regarding student safety once a campaign or protest has been announced. For their part, vocal lecturers can be found defending certain speakers but it is relatively rare to find robust arguments for an open campus and a free for all of ideas.

\section{Protecting the vulnerable}

The examples listed above keep growing, and even as I write this paper there are more examples, regarding the banning of speakers and protests to limit the 'offensive' nature of university life.

One specific example of the change to the curriculum under the guise of protecting vulnerable students can be seen in the Sociology A Level in England. Here, the classical work of Emile Durkheim - examining the issue of suicide, and which has been taught for decades - has now been dropped. The reason for this, as Rupert Sheard, AQA qualifications 
manager, explained, is because of what he called a 'a duty of care to all those students taking our course to make sure the content isn't going to cause them undue distress'. As Ged Flynn, chief executive of Papyrus, a charity working to prevent youth suicide argued in response to this:

Why are they removing this part of the syllabus? It's not because Durkheim has suddenly become less important. It's been dropped because people feel uncomfortable teaching about suicide because of the stigma and pain. But suicide won't go away if we feel sensitive about it. Teachers need to get over themselves or get a new job (Guardian, 2015).

This growing belief that students are vulnerable and need to be kept safe reflects a wider cultural sensitivity about words and ideas and about the emotional harm caused by them. The use of, what has now become known as the ' $n$ ' word, has been banned from the BBC. Newspapers in the UK are taking a similar editorial policy. Regardless of context or even if the ' $\mathrm{n}$ ' word is to be discussed as part of an anti-racist discussion the word itself has been institutionally adorned as an 'offensive' word. What then for universities or lecturers who wish to discuss race, racism or plan to use material with this word in the text? What about other words that are offensive or make some students feel uncomfortable? Will our students begin complaining about terms or issues that make them feel 'uncomfortable'? And if they do will management support the students or alternatively will they support academic freedom and perhaps explain, as Benjamin Disraeli did, that, 'A university is a place of light, of liberty, and of learning'? 
When first writing this chapter I concluded that some of the issues raised here are more relevant to the USA than the UK, noting that it is worth bearing in mind that the US has the First Amendment and the UK does not and that in that respect UK laws are actually far worse than those in the US, despite developments in American university campuses. However, in a relatively short space of time I would now conclude that the UK is competing with the US on this issue and in some respects may be leading the way in their protection of students from offensive words and ideas. A number of UK laws, a number of universities and many student associations in the UK are highly censorious and appear to be increasingly so, often within the framework of protecting students from things that are deemed to be offensive. As words and ideas increasingly become associated with negative feelings it will be up to lecturers, management and indeed students themselves to defend both free speech and academic freedom and that means defending the expression of views and ideas we may often disagree with. If this is not forthcoming the climate of offence taking is likely to increase: And note that in 2007 a UK survey found that 64 percent of the British public surveyed supported the right of people, 'not to be exposed to offensive views'. This contrasted to 54 percent of people who said people should have the right to 'say what they think' (Hume, 2015, pp. 49).

\section{Conclusion}

It is difficult to judge what will happen to academic freedom. In the UK for example a Free Speech Union has recently been formed to challenge many of the issues raised in this paper. We will have to wait and see if this will act as a barrier to the corrosion of this freedom.

Historically there appears to be a dialectical relationship between the diminishing sense of human possibilities through collective political action, and the diminishing individual subject 
seen with the emergence of the 'vulnerable student'. Liberalism was about the individual but it was a universal-societal individual that inspired John Stuart Mill's belief in liberty. In the twentieth century Mill's passion and belief in freedom was taken up by alternative left and radical voices but this optimism was short lived. As the belief in social transformation declined so too did the liberal/radical defence of freedom of speech and academic freedom indeed it was often on the left that arguments developed that challenged these 'bourgeois freedoms'. Alongside these developments, though less clearly scrutinised, the norm of Mill's robust liberal subject has diminished and human subjectivity, in general rather than simply in terms of 'vulnerable groups' is now comprehended through the presumption of a universal vulnerability. In other words, with the hollowing out of political ideas and organisations we have witnessed a diminishing of the belief in individual freedom and tolerance and a diminishing, or at least a presumption, of diminished individual capacity or subjectivity. And the diminished, vulnerable subject needs safety and protection far more than it desires freedom.

Over time, the academic assault on Truth has helped to construct a relativistic academic culture and has helped to transform the very meaning of liberal categories like tolerance. Today's tolerant liberals are at the forefront of the assault on genuine tolerance and academic freedom, and have helped to portray freedom of speech as a right wing issue. These illiberal trends have been accelerated in the last decade by the emergence of a new generation of student activists, often oriented around identity politics, who not only carry the fragmented and relativistic sensibility of their academic elders but also embody more acutely the postmodern sensibility of vulnerability. Sometimes opportunistically or cynically used, these students nevertheless experience the vulnerability of a society that no longer believes in beliefs. 
The third dimension of modern restrictions of academic freedom come from university administrators who are equally confused about the meaning of truth and indeed of freedom and tolerance. Lacking a clarity of purpose, like many other modern institutions, they have tended towards safety based policies coupled with a more therapeutic engagement with students. Helped by the push of modern student activists and the relativistic academic culture, universities increasingly play it safe and can at least feel confident that in keeping vulnerable students safe, they are following 'best practice'.

The result is a conformist culture where restrictions on academic freedom come less from a powerful ideology than from a need to ensure that everyone is 'aware' of everyone else's vulnerability.

One of the more aggressive, vibrant, offensively intelligent and yet still well humoured debates I have watched is that between the American author Norman Mailer and Germaine Greer that took place in New York Town Hall in 1971. A debate like this should be what universities aspire towards for their students. Sadly, I suspect the triumvirate of identity activism, a relativistic academic culture overseen by a therapeutic university management, all coalescing around the 'vulnerable student', make this type of event less and less likely today. Mailer's aggressive style and questioning of women's liberation would be 'unsafe' but also today, we would find the feminist Greer facing a possible ban for transphobia. Greer's crime is that of stating that a person with a penis is not a woman. Something that until recently was recognised as a biological fact, through a therapeutic lens is no longer a truth but another affront to the emotional wellbeing of a self-identifying group of 'vulnerable' individuals. 


\section{References}

Adler, A. (1996). What's Left?: Hate Speech, Pornography, and the Problem for Artistic Expression. California Law Review 84(6), 1499-1572.

AFAF. (2020). Heroes and Zeros. https://www.afaf.org.uk/heroes-and-zeros/

Alexander, N. (2014, December 5). 'I Am No anti-Semite' Says Steven Salaita, Lecturer-cum Celeb Who Was Fired for Tweeting. Haaretz. http://www.haaretz.com/israel-news/.premium1.630098

Altbach, P.G. (2001). Academic freedom: International realities and challenges. Higher Education, 41, 205-219.

American Association of University Professors. (1915). APPENDIX I: 1915 Declaration of Principles on Academic Freedom and Academic Tenure. https://www.aaup.org/NR/rdonlyres/A6520A9D0A9A-47B3-B550-C006B5B224E7/0/1915Declaration.pdf

BBC. (2015). Paris attacks: France grapples with freedom of speech. http://www.bbc.co.uk/news/blogs-eu-30829005

Boostrom, R. (1998). 'Safe spaces': reflections on an educational metaphor. Curriculum Studies 30(4), 397-408. 
Bristol SU. (2016, July 28). Safe Space Policy Reform Motion 2016.

https://www.bristolsu.org.uk/resources/safe-space-policy-reform-motion-2016

Cole, D. (2015, November 18). Yale: The Power of Speech. The New York Review. $18^{\text {th }}$ November. http://www.nybooks.com/daily/2015/11/18/yale-power-of-speech/

Coleman, P. (2012). How European “Hate Speech” Laws Threaten Freedom of Speech. Karios Publications.

Durodie, B. (2016). Securitising education to prevent terrorism. Or losing direction? British Journal of Educational Studies. 2016. In Press.

Eagleton, T. (2014). Culture and the Death of God. Yale University.

Ecclestone, K. (2016) Changing the Subject: The rise of 'Vulnerable' Students'. In C. Hudson \& J. Williams (Eds.), Why Academic Freedom Matters. Civitas.

Engage. (2015). For the record - Israel matters at UCU Congress 2015. https://engageonline.wordpress.com/2015/05/26/for-the-record-israel-matters-at-ucucongress-2015/

Flaherty, C. (2013, November 25). In Class Sit-In. https://www.insidehighered.com/news/2013/11/25/ucla-grad-students-stage-sit-during-classprotest-what-they-see-racially-hostile 
Friedersdorf, C. (2015, November 10). Campus Activists Weaponize 'Safe Space'. The Atlantic.

Furedi, F. (1992). Mythical Past Elusive Future. Pluto Press.

Furedi, F. (1997). Culture of Fear. Continuum.

Furedi, F. (2004). Where have all the intellectuals gone. Continuum.

Furedi, F. (2007). First World War: Still No End In Sight. Continuum.

Furedi, F. (2011). On Tolerance: A Defence of Moral Independence. Continuum.

Furedi. (2017). What's happened to the university. Routledge.

Garrison, B. (2015). Attack of the Cry Bullies.

https://grrrgraphics.wordpress.com/2015/11/13/attack-of-the-cry-bullies-new-ben-garrisoncartoon/

Grant, G. (2019, October 26) Students’ Fairytale Warning. Scottish Daily Mail.

Griswold, A. (2015, November 10). University of Missouri Police Ask Students to Report ‘Hurtful Speech'. Mediaite. 
Guardian. (2014, March 5). We've gone too far with 'trigger warnings'.

https://www.theguardian.com/commentisfree/2014/mar/05/trigger-warnings-can-becounterproductive

Guardian. (2015). Guardian Live| Queens of Jihad: victims of terror grooming or mistresses of their own fate? https://membership.theguardian.com/event/guardian-live-queens-of-jihadvictims-of-terror-grooming-or-mistresses-of-their-own-fate-17635345794

Hafez, R. (2016). Faith in the Academy: Religion at University. In C. Hudson \& J. Williams (Eds.), Why Academic Freedom Matters. Civitas.

Harcourt, B. E. (1999) The Collapse of the Harm Principle. Journal of Criminal Law and Criminology, 90(1), 109-194.

Heartfield, J. (2017). The Equal Opportunities Revolution. Repeater.

Holley, L.C., \& Steiner, S. (2005). Safe Space: Student Perspectives on Classroom Environment, Journal of Social Work Education, 41(1), 49-64.

Home Office (2019) Revised Prevent duty guidance: for England and Wales. https://www.gov.uk/government/publications/prevent-duty-guidance/revised-prevent-dutyguidance-for-england-and-wales

Hudson, C. \& Williams, J. (2016). Why Academic Freedom Matters. Civitas. 
Hume, M. (2019, August 8). Press freedom matters more than jailing Shamima Begum. https://www.spiked-online.com/2019/08/08/press-freedom-matters-more-than-jailingshamima-begum/

Hunt, I. (2015, February 6). Safe space or free speech? The crisis around debate at UK universities. Guardian. https://www.theguardian.com/education/2015/feb/06/safe-space-orfree-speech-crisis-debate-uk-universities

Jarvey, J. (2016). Warning: on Campus, a Fear of Words and Ideas. In Hudson, C. \& Williams, J. (Eds.), Why Academic Freedom Matters. Civitas.

Jacoby, R. (1999). The End of Utopia Politics and Culture in an Age of Apathy. Basic Books.

Locke, J. (1946). The Second Treatise of Government and A Letter Concerning Toleration. Blackwell.

Lukianoff. G. (2014). Unlearning Liberty: Campus Censorship and the End of American Debate. Encounter.

MacDonald, H. (2014). The Microaggression Farce. City Journal. Autumn. http://www.city-journal.org/2014/24_4_racial-microaggression.html.

Marcuse, H. (1972). Eros and Civilisation. Abacus.

Mill, J.S. (2011). On Liberty. Walter Scott Publications. 
Available online at http://www.gutenberg.org/files/34901/34901-h/34901-h.htm

Namazi, M. (2015, December 3). Goldsmiths University Islamist thugs fail to disrupt speech on blasphemy and apostasy. [Video]. https://www.youtube.com/watch?v=-1ZiZdz5nao

O’Neill, B. (2015, November 6). Why are student-union officials censoring criticism of Islamic State?. The Spectator.

http://blogs.spectator.co.uk/2015/11/why-are-student-union-officials-censoring-criticism-ofislamic-state/

O’Neill, (2015a, November 20). As David Starkey is the latest to be banned by our politically correct universities... Britain's students: the new fascists? Daily Mail. http://www.dailymail.co.uk/debate/article-3326397/As-David-Starkey-latest-bannedpolitically-correct-universities-Britain-s-students-new-fascists.html\#ixzz3sWOHT4I9

Orwell, G. (2000). 'The Freedom of the press'. In Animal Farm. Penguin. http://orwell.ru/library/books/htm_file/015

Oxford SU. Resource Hub: Trigger Warnings.

https://www.oxfordsu.org/resourcehub/guidetotriggerwarnings/

Rooney, K. (2018). A victory for freedom and football fans https://www.spikedonline.com/2018/03/19/a-victory-for-freedom-and-football-fans/ 
Slater, T. (2015, February 3). Free Speech University Rankings: Exposing the staggering scale of censorship on campus. Spiked online. http://www.spiked-

online.com/newsite/article/exposed-the-staggering-scale-of-censorship-oncampus/16658\#.VlyY4dLhCM8

Slater, T. (2016, January 15) The Tyranny of Safe Spaces. Spiked online. https://www.spikedonline.com/2016/01/15/the-tyranny-of-safe-spaces/

Slater, T. (2020, January 15) Beware the university campus microaggression monitors. The Spectator. https://retro-blogs.spectator.co.uk/2020/01/beware-the-university-campusmicroaggression-monitors/

Sue, D.W., Capodilupo, C.W., Torino, G.C., Bucceri, J.M., Holder, A.M.B., Nadal, K.L. and Esquilin, M. (2007). Racial Microaggression in Everyday Life. American Psychologist, 62 (4), 271-286.

http://www.consumerstar.org/resources/pdf/RacialMicroaggressions.pdf

Stack, L. (2015, November 8). Yale's Halloween Advice Stokes a Racially Charged Debate. The New York Times. http://www.nytimes.com/2015/11/09/nyregion/yale-culturally-insensitive-halloweencostumes-free-speech.html?_r=2

Stanford Encyclopedia of Philosophy. (2017) Freedom of Speech. https://plato.stanford.edu/entries/freedom-speech/ 
Tumblr. (2016, April 2). I, too, am Oxford. https://itooamoxford.tumblr.com/

UCLA (2010). Tool: Recognizing Microaggressions and the Message they Send. http://academicaffairs.ucsc.edu/events/documents/Microaggressions_Examples_Arial_2014_ 11_12.pdf

UCU. (2015). The Prevent Duty. https://www.ucu.org.uk/media/7370/The-prevent-dutyguidance-for-branches-Dec-15/pdf/ucu_preventdutyguidance_dec15.pdf

Waiton, S. (2012). Snobs Law: Criminalising Football Fans in an Age of Intolerance. Take a Liberty.

Waiton, S. (2019). The Vulnerable Subject. Societies, 9(3).

Walsh, J. (2015, June 5). The Expanding Empire of Harm. [Conference Paper] AMNESTY INTERNATIONAL EVENT CRESCENT ARTS CENTRE, BELFAST.

Williams, J. (2013, December 9). Teaching students to fear free speech. Spiked online. https://www.spiked-online.com/2013/12/09/teaching-students-to-fear-freespeech/\#.V129t9LhCM8 